\title{
AS INSTITUIÇÕES FINANCEIRAS E SUA RELAÇÃO COM AS FINTECHS NO BRASIL
}

\section{FINANCIAL INSTITUTIONS AND THEIR RELATIONS WITH FINTECHS IN BRAZIL}

\author{
Lucas Leão Silva \\ Banco do Brasil/PUC Minas \\ lucasleaodasilva@hotmail.com \\ Erika Farias Lisboa \\ Uniceub-Brasília \\ erika.lisboa@uniceub.br \\ Luciene Braz Ferreira \\ PUC Minas \\ lucieneraz@yahoo.com.br \\ Ângela França Versiani \\ PPGA-PUC Minas \\ versiani@pucminas.br \\ Paulo Renato Sousa \\ FDC - Fundação Dom Cabral \\ paulorenato@fdc.org.br \\ Marcelo Lisboa Cordeiro \\ Uniceub-Brasília \\ cordeiromarcelo@yahoo.com.br
}

Submissão: $30 / 07 / 2019$

Aprovação: 04/08/2020

\section{RESUMO}

O estudo realizado tem como objetivo identificar como as Fintechs se caracterizam como oportunidades e ameaças para as grandes instituições financeiras no Brasil. A fim de compreender e analisar os aspectos relacionados às Fintechs, a pesquisa aborda tópicos alinhados ao tema, como o contexto atual da economia, o Sistema Financeiro Nacional e o cenário de startups no Brasil. Este estudo possui caráter descritivo e qualitativo, no qual os dados foram coletados a partir da realização de entrevistas com os responsáveis por instituições financeiras. A pesquisa permitiu identificar que há a aceitação por parte das grandes instituições para aplicação desse modelo de Fintechs. Observou-se também que há uma necessidade de regulamentação do setor para que o mesmo possa crescer com mais liberdade e assim podendo acrescentar ao país essa riqueza tecnológica, porém, analisa a necessidade de ser menos burocrático como as instituições financeiras atuantes no mercado. $\mathrm{O}$ estudo apresentou como limitações a apresentação de poucos casos, em que não foi possível 
entrevistar mais gerentes em outras empresas que estão envolvidas de alguma forma com as inovações da organização. A partir desta situação, sugere-se que outros estudos sejam realizados para cobrir outros pontos interessantes que digam respeito ao modelo de negócio Fintechs. O estudo permitiu compreender como as grandes empresas já estabelecidas no mercado financeiro identificam as Fintechs e seus modelos de negócios. A identificação de oportunidades e de ameaças e como se dá esse entendimento permitindo que as Fintechs se preparem para um mercado competitivo e que grandes empresas entendam como este modelo pode ser caracterizado como aliado. Em relação à originalidade, vários estudos foram desenvolvidos no âmbito do mercado financeiro. No entanto, ao pesquisar em bases de dados científicas, o assunto sobre Fintechs é pouco explorado assim como a percepção de seu modelo de negócios por outros players do setor.

Palavras-chave: fintech, banco, empreendedorismo, startup, finanças

\begin{abstract}
The study aims to identify how Fintechs are characterized as opportunities and threats for large financial institutions in Brazil. In order to understand and analyze aspects related to Fintechs, the research addresses topics aligned with the theme, such as the current economic context, the National Financial System and the startup scenario in Brazil. This study has a descriptive and qualitative character, in which data were collected from interviews with those responsible for financial institutions. The research showed that there is acceptance by large institutions to apply this model of Fintechs. It was also noted that there is a need for regulation of the sector so that it can grow more freely and thus can add to the country this technological wealth, however, analyzes the need to be less bureaucratic as the financial institutions operating in the market. The study's limitations were the presentation of a few cases in which it was not possible to interview more managers in other companies that are involved in some way with the organization's innovations. From this situation, further studies are suggested to cover other interesting points concerning the Fintechs business model. The study allowed us to understand how large companies already established in the financial market identify Fintechs and their business models. Identifying opportunities and threats and understanding this allows Fintechs to prepare for a competitive market and for large companies to understand how this model can be characterized as an ally. Regarding originality, several studies were developed within the financial market. However, when searching in scientific databases, the subject of Fintechs is little explored as well as the perception of its business model by other players in the sector.
\end{abstract}

Keyword: fintech, bank, entrepreneurship, startup, finance

\title{
1 INTRODUÇÃO
}

Os avanços tecnológicos têm impactado todas as áreas do mercado. Não sendo diferente quando se trata do mercado financeiro. Conhecido como um mercado tradicional e burocrático, o Brasil se depara, no momento, com o surgimento e a expansão da atuação das Fintechs e suas soluções para a área financeira.

Por outro lado, as grandes empesas, já atuantes e consolidadas no mercado se deparam com a necessidade de se adequarem, se adaptarem ou se reinventarem frente a seus stakeholders. 
No desafio que se tornou o mercado na área financeira, essas pequenas organizações surgiram para desafiar grandes instituições financeiras já consolidadas no mercado, pois não havia modelos novos que pudessem competir com esse sistema. Com um início modesto, o modelo alcançou expressividade no mercado financeiro e se tornou uma aposta para instituições interessadas no avanço tecnológico e social.

O serviço trazido por essas Fintechs tende a alcançar mercado com seus produtos e serviços que podem oferecer desde cartão de crédito a empréstimos pessoais sem burocracia, desafiando os bancos com sua diferenciação de negócio eficiente. Essas empresas investem na tecnologia e trabalham de forma mais rápida e transparente.

Frente ao exposto, o artigo busca responder ao seguinte problema de pesquisa: As Fintechs se configuram como oportunidades ou como ameaças para as grandes instituições financeiras no Brasil?

Para responder ao problema proposto, o objetivo geral dessa pesquisa é identificar como as Fintechs se configuram oportunidades ou ameaças para as grandes instituições financeiras no Brasil. E como objetivos específicos: analisar as percepções sobre as Fintechs; observar as parcerias que podem surgir entre as instituições financeiras e as Fintechs; identificar os desafios das Fintechs com o mercado.

A relevância acadêmica desse trabalho justifica-se pela atualidade do tema, pela pouca quantidade de pesquisa relacionada ao assunto e pelo crescimento exponencial de Fintechs no mercado. Sendo assim, a pesquisa agregará ao meio acadêmico como incentivo ao estudo científico. Socialmente e economicamente o estudo trará mais conhecimentos para esses tipos de organizações que buscam empreender por meio das Fintechs que estão em grande expansão.

Portanto, a seguir será apresentado o referencial teórico e todo seu embasamento científico para o alcance dos objetivos propostos.

\section{REFERENCIAL TEÓRICO}

\subsection{Fintech}

De acordo com Alecrim (2017), o termo Fintech surge de uma combinação entre as palavras em inglês financial (finanças) e technology (tecnologia). O termo, por si só, resume bem a ideia das Fintechs, visto que são todas as empresas que oferecem serviços financeiros que se diferenciam pelas facilidades proporcionadas pela tecnologia e, com efeito, pela internet.

Em seu artigo publicado em 2015 sobre a evolução das Fintechs, Arner et al (2015) afirmam que a origem deste termo «Fintech» pode ser rastreada até o início da década de 1990 e se referiu ao Consórcio de Tecnologia de Serviços Financeiros, um projeto iniciado pelo Citigroup para facilitar os esforços de cooperação tecnológica. Em um artigo publicado no American Banker por Kutler (1993) sobre o Citgroup, com o título de Friday Flashback: Citi Coin the Term 'Fintech'?, em agosto de 1993, consta o suposto primeiro aparecimento da palavra Fintech, de acordo com Hochstein (2015).

No entanto, o termo já tinha sido usado em 1972. Em um artigo acadêmico escrito por Bettinger (1972), onde ele detalhava modelos sobre como havia analisado e resolvido os problemas bancários diários encontrados no banco Manufacturers Hanover Trust. Denominou Fintech como sendo um acrônimo que representa tecnologia financeira, combinando conhecimentos bancários com modernas técnicas de ciência de gestão e o computador. Uma citação inicial do trabalho de Bettinger (1972) por Warschauer (1974) também prova que o estudo de Bettinger não passou inteiramente despercebido durante seus tempos. 
Ao lado das explicações da palavra Fintech que emana dos anos setenta e noventa do século passado, uma infinidade de conceitos para o termo foi proposta nos últimos anos. Num conceito inicial, Barberis (2014) apresenta que Fintech é um setor emergente de serviços financeiros que inclui pagamentos de terceiros, empréstimos, produtos de seguros, gerenciamento de riscos e autenticação. De forma complementar, Arner et al (2015) trazem que Fintech correspondente à designação de empresas que disponibilizam serviços ou soluções financeiras potenciadas pela tecnologia e que vieram demonstrar um novo paradigma. Nesta linha, Walker (2014) conclui que o sistema financeiro continuará a ser absolutamente necessário, porém, os bancos como são conhecidos, não serão necessários na mesma medida, podendo muitos serviços serem prestados por estas novas empresas.

No contexto de complementariedade dos serviços e embora não haja muita diferença entre os serviços oferecidos pelas instituições bancárias tradicionais, que já trabalham com alta tecnologia para atribuir acesso e segurança às transações financeiras, as Fintechs estão tirando proveito de algumas oportunidades. Segundo Alecrim (2016), Barquin (2016) e Alves (2016) nas Fintechs a tecnologia é utilizada essencialmente para trazer conveniência por meio da inovação, ou seja, as empresas do ramo utilizam recursos tecnológicos amplamente disseminados para criar metodologias, processos e ferramentas que facilitam o acesso aos serviços financeiros. $\mathrm{O}$ resultado aparece para o cliente na forma de praticidade, burocracia reduzida, custos baixos e maior controle sobre operações financeiras. A grande vantagem do emprego dessas tecnologias disruptivas é que podem ser feitas com pouco ou nenhum investimento em ativo físico: seu produto é uma plataforma, ou seja, o serviço é disponibilizado muitas vezes por meio de uma estrutura que o próprio cliente já possui, como no caso de um smartphone.

Nesta linha, Chuen e Teo (2016) apresentam que as sete principais características dos modelos de negócio trazidos pelas Fintechs são: i) orientação centrada nos clientes, onde os produtos e serviços são fáceis de usar e de alta conveniência, as proposições são centradas nas necessidades desenhadas em torno das particularidades dos casos de consumo e pontos de dor e ocorre um alto grau de engajamento com os clientes; ii) ausência de legados tecnológicos que dificultam ou mesmo impedem a evolução, uma vez que os sistemas são construídos em torno de canais digitais e atendimento; iii) poucos ativos fixos sendo empresas apoiadas em modelos de outsourcing, negócio com poucas exigências de capital; iv) escalabilidade incorporada ao modelo de negócios alavancando parcerias, distribuição e simplicidade; v) simplicidade da proposta de valor e fatores diferenciadores fáceis de compreender pelos clientes com processos de negócios altamente focados e transparentes; vi) inovação como matriz principal, seja na adoção tecnológica ou na criação de novos modelos de negócio, produtos e serviços e modelos de entrega; e vii) modelos de negócios pensados para evitar a exposição à regulação imposta ao setor financeiro.

A relevância deste segmento de empresas do ramo financeiro tem sua importância apresentada por Hwang (2014) por meio do investimento global realizado em Fintechs, que triplicou em cinco anos, passando de 920 milhões de dólares, em 2008, para 2,97 bilhões de dólares, em 2013. Outro fator que demonstra a importância das Fintechs no contexto atual é a quantidade de consultas que o termo Fintech recebe mensalmente em website de busca, que atinge, em média, aproximadamente 201 mil pesquisas em todo o mundo (GOOGLE, 2016). Essa contagem pode não parecer grande, especialmente ao compará-la ao termo "banco", que em 2016 atingiu mais de 2,24 milhões de solicitações de pesquisa por mês. No entanto, é um número bastante considerável em comparação ao termo "serviços financeiros", que atinge aproximadamente 40,5 mil contagens globais mensais (GOOGLE, 2016).

O estudo realizado por Puschmann (2017) apresenta de forma prática e aplicada a diversos estudos teóricos (TUFANO, 2003; FRAME, WHITE 2014; ALT, SACHSE, 2012; 
GIMPEL, RAU, RÖGLINGER, 2016; HADDAD, HORNUF, 2016) as três dimensões das Fintechs, sendo elas: i) objeto de inovação; ii) grau de inovação; e iii) escopo de inovação. Como as soluções das Fintechs estão intimamente relacionadas com inovações financeiras em relação a produtos e serviços, organizações, processos, sistemas e modelos de negócios, elas geralmente diferem em relação a esses objetos. Uma visão mais abrangente é dada quando complementada pelo grau de inovação de dimensões e pelo escopo de inovação, conforme observado na figura 1.

\section{Objeto da Inovação}

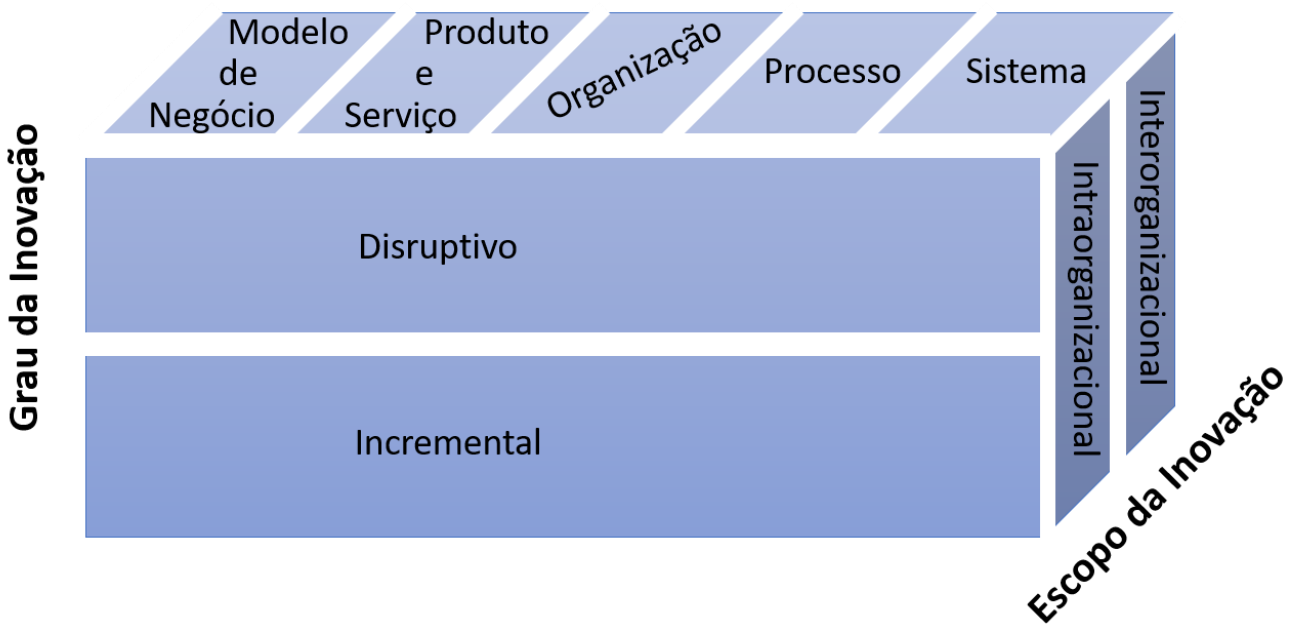

Figura 1: Composição e segmentos do Sistema Financeiro Nacional

Fonte: Adaptado de Puschmann (2017)

De acordo com as cinco categorias de inovações financeiras como modelo de negócio, produto e serviço, organização, processo e sistema, estas podem ser distinguidas como os principais objetos de inovação para as Fintechs (MORI, 2016).

A tecnologia em geral e as Fintechs especialmente podem sofrer diferentes efeitos de desempenho que podem ser incrementais ou disruptivos (FOSTER, 1986). Embora as soluções das Fintechs incrementais conduzam a uma otimização do status quo em relação à qualidade, tempo e custo, as tecnologias disruptivas geralmente apresentam desempenho inferior nos estágios iniciais de sua evolução, mas em seu desenvolvimento posterior levam a mudanças fundamentais de toda a cadeia de valor (BOWER, CHRISTENSEN, 1995).

As inovações das Fintechs diferem em relação ao seu alcance sendo intra ou interorganizacional. Embora as inovações intraorganizacionais se concentrem em mudanças internas e microeconômicas de objetos de inovação em uma das cinco categorias, as inovações interorganizacionais se concentram em estruturas macroeconômicas com mudanças na cadeia de valor.

Compilando estas três dimensões, Puschmann (2017) define o termo Fintech de forma mais abrangente harmonizando as demais percepções apontadas anteriormente. No contexto do setor de serviços financeiros, as Fintechs são como inovações incrementais ou disruptivas induzidas por desenvolvimentos de tecnologia da informação, resultando em novos modelos de negócios intra ou inter-organizacionais, produtos e serviços, organizações, processos e sistemas.

Na visão global das Fintechs, de acordo com o relatório BargainFox de 2016, os principais países que apresentam este ecossistema são os Estados Unidos (Silicon Valey, Nova York, Los Angeles e Boston), Inglaterra (Londres) e Israel (Tel Aviv). Entre 2010 e 2015, cerca de US\$ 50 bilhões foram investidos em todo o mundo, com investimentos concentrados nos Estados Unidos (US \$ 31 bilhões). O mercado sul-americano, liderado pelo 
Brasil, recebeu apenas US\$ 100 milhões, mostrando que o ecossistema ainda é incipiente na região, como pode ser visto na Figura 2.

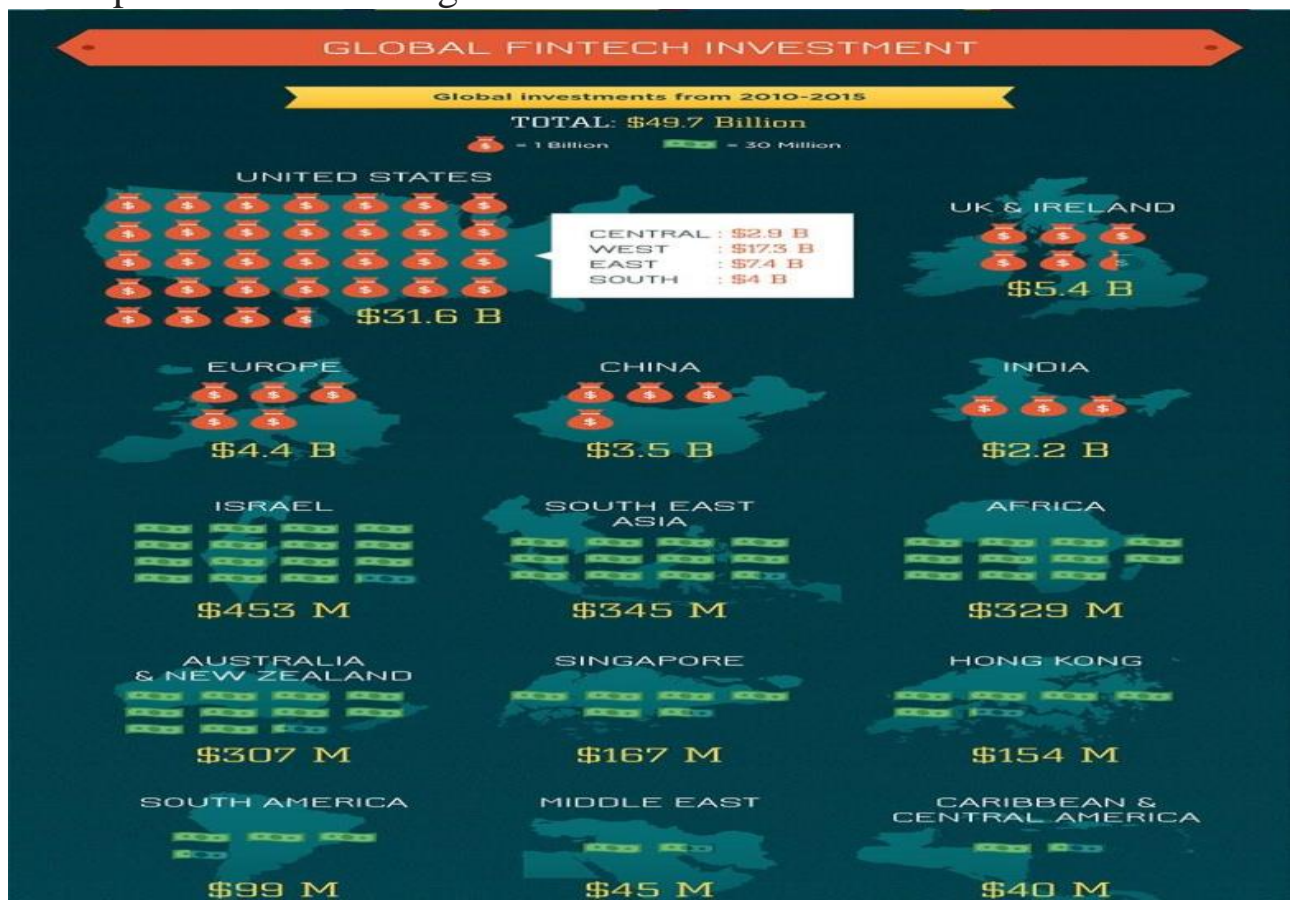

Figura 2 - Global Fintechs Investment

Fonte - BargainFox

Esse cenário vem evoluindo com o número de Fintechs que estão aparecendo no mercado brasileiro de acordo com o último radar Fintechlab que mostra um crescimento de $30 \%$ nas Fintechs no Brasil, conforme percebido na figura 3.

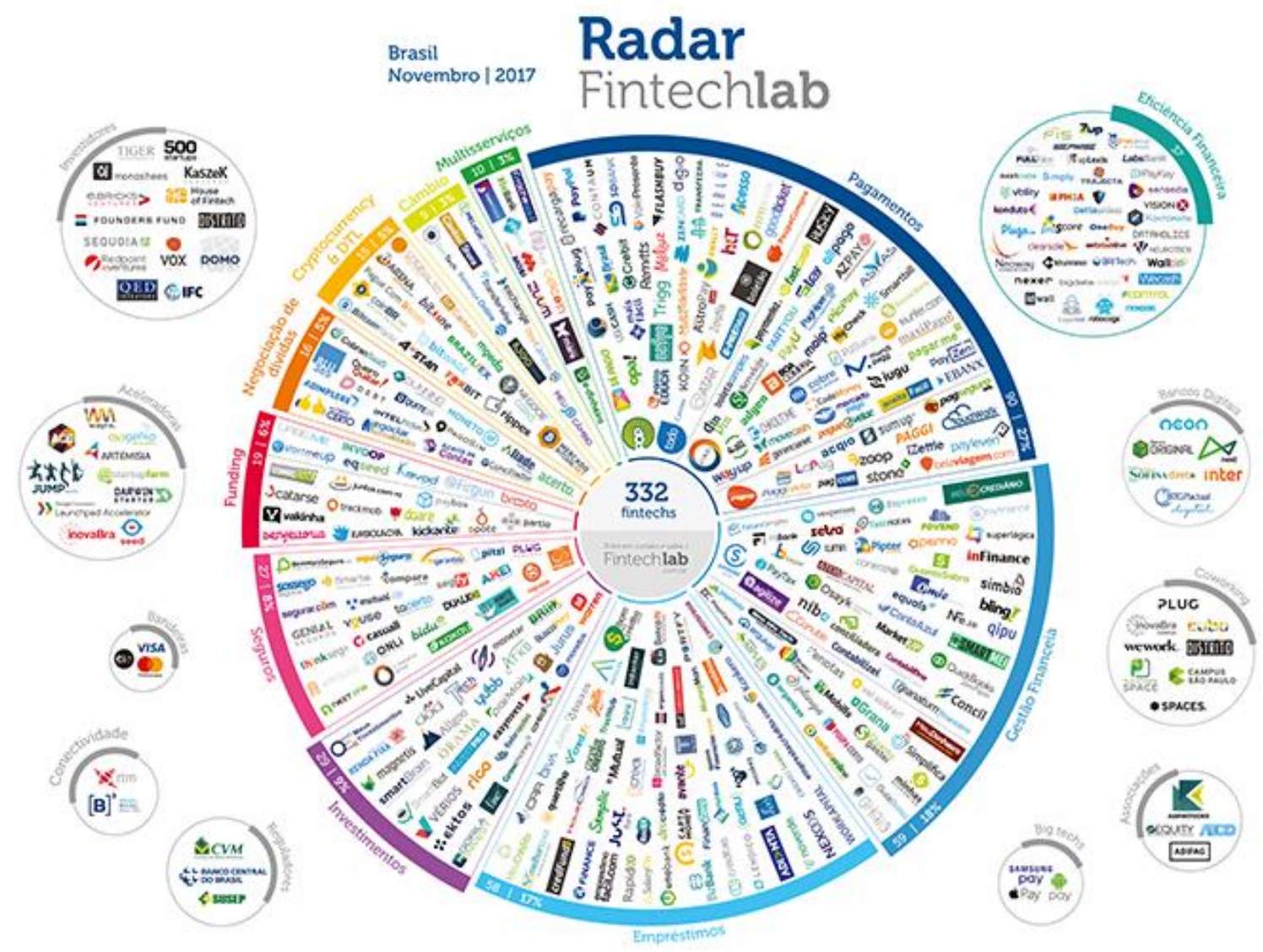


Figura 3 - Mapa das Fintechs no Brasil

Fonte - Fintechlab

\subsection{Sistema Financeiro e as Fintechs}

O sistema financeiro é um conjunto de instituições e instrumentos financeiros que possibilita a transferência de recursos dos poupadores, que dispõem de valores financeiros aos tomadores finais. Tal conceito e dinâmica, apontados por Cavalcante (2002), criam condições para que os títulos e valores mobiliários tenham liquidez no mercado.

Para garantir todo este funcionamento, Hillbrecht (1999) ressalta que o sistema financeiro é um dos setores mais regulados do mundo, existindo três motivos básicos para tal regulação: i) aumentar a informação disponível aos investidores; ii) garantir o adequado funcionamento do sistema financeiro; e iii) melhorar o controle sobre a oferta de moeda.

No Brasil, o Sistema Financeiro Nacional (SFN) não é diferente em sua regulação. Órgãos de controle, entidades e operadoras, conforme figura 4, têm as funções de determinar regras gerais seguindo a regulamentação empregada no setor para o bom funcionamento do SFN; atuar para que os cidadãos e os integrantes do sistema financeiro sigam as regras definidas pelos órgãos normativos e lidar diretamente com o público no papel de intermediário financeiro (BACEN, 2017).

\begin{tabular}{|c|c|c|c|c|}
\hline & \multicolumn{2}{|c|}{ Moeda, crédito, capitais e câmbio } & Seguros privados & Previdência fechada \\
\hline 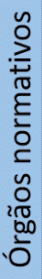 & \multicolumn{2}{|c|}{ CMN - Conselho Monetário Nacional } & $\begin{array}{l}\text { CNSP - Conselho } \\
\text { Nacional de } \\
\text { Seguros Privados }\end{array}$ & $\begin{array}{l}\text { CNPC - Conselho } \\
\text { Nacional de } \\
\text { Previdência } \\
\text { Complementar }\end{array}$ \\
\hline 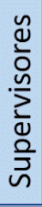 & BCB - Banco Central do Brasil & $\begin{array}{l}\text { CVM - Comissão da } \\
\text { Valores Mobiliários }\end{array}$ & $\begin{array}{c}\text { SUSEP - } \\
\text { Superintendência } \\
\text { de Seguros } \\
\text { Privados }\end{array}$ & $\begin{array}{c}\text { Previc - } \\
\text { Superintendência } \\
\text { Nacional de } \\
\text { Previdência } \\
\text { Complementar }\end{array}$ \\
\hline 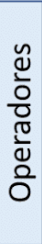 & $\begin{array}{l}\text { Bancos e caixas econômicas } \\
\text { Administradoras de consórcios } \\
\text { Cooperativas de crédito } \\
\text { Corretoras e distribuidoras } \\
\text { Instituições de pagamentos } \\
\text { Demais instituições não bancárias }\end{array}$ & $\begin{array}{l}\text { Bolsa de valores } \\
\text { Bolsa de mercadorias } \\
\text { e futuros }\end{array}$ & $\begin{array}{l}\text { Seguradoras e } \\
\text { resseguradoras } \\
\text { Entidades abertas } \\
\text { de previdência } \\
\text { Sociedades de } \\
\text { capitalização }\end{array}$ & $\begin{array}{l}\text { Entidades fechadas } \\
\text { de previdência } \\
\text { complementar } \\
\text { (fundos de pensão) }\end{array}$ \\
\hline
\end{tabular}

Figura 4: Composição e segmentos do Sistema Financeiro Nacional

Fonte: Adaptado de BACEN (2017)

O Sistema Financeiro Nacional (SFN) pode ser subdivido em entidades normativas, supervisoras e operacionais. As entidades normativas são responsáveis pela definição das políticas e diretrizes gerais do sistema financeiro, sem função executiva. As entidades supervisoras, por outro lado, assumem diversas funções executivas, como a fiscalização das instituições sob sua responsabilidade, assim como funções normativas, com o intuito de regulamentar as decisões tomadas pelas entidades normativas ou atribuições outorgadas a elas diretamente pela Lei. Além destas, há as entidades operadoras, que são todas as demais instituições financeiras, monetárias ou não, oficiais ou não, como também demais instituições auxiliares, responsáveis, entre outras atribuições, pelas intermediações de recursos entre poupadores e tomadores ou pela prestação de serviços.

Como o advento da crise de 2008 que assolou vários países, foram impostas reformas aos bancos pelos órgãos reguladores que acabaram por limitar suas capacidades de direcionar 
investimentos para o processo de inovação, devido principalmente aos acordos de Basiléia, abrindo espaço para o nascimento das Fintechs.

Outro ponto de destaque foi o surgimento de novos modelos de negócio que operam ainda em muitos países fora do modelo de regulação, como os empréstimos entre pessoas diretamente, sem a figura do intermediador financeiro, mas baseado no modelo de Fintech (ARNER, BARBERI, BUCKLER, 2015).

Neste contexto, mas já no ambiente regulatório do SFN, a Resolução n $^{\circ} .4 .480$ do Banco Central do Brasil, regulamentada pelo Conselho Monetário Nacional (CMN), em abril de 2016, que dispõe sobre a abertura e o encerramento de contas de depósitos por meio eletrônico, permitiu aos brasileiros a abertura de conta corrente e caderneta de poupança via internet. Essa movimentação lançou um novo cenário competitivo, trazendo os bancos para uma nova era de competitividade, impondo uma atuação mais agressiva. Para acompanhar o desenvolvimento e o avanço frente aos novos meios de acesso e atendimento os bancos buscaram a adoção de plataformas digitais amigáveis e eficientes para que, assim, pudessem conter os avanços das Fintechs.

Portanto, percebe-se que as Fintechs apresentam muitos dos princípios de estratégia e inovação defendidos por Porter (1991), Drucker (2002) e Christensen (2015). Muitos desses conceitos estão presentes em seus novos modelos de negócio e possibilitaram criar disrupção e inovação na indústria financeira.

\section{MÉTODO}

O estudo realizado foi descritivo que, segundo Gil (2010), tem o propósito de proporcionar ao pesquisador uma descrição detalhada das características da organização. Malhotra (2012) aborda que a pesquisa descritiva possui um objetivo em descrever essas características que poderão ser uma concepção pré-definida e estruturada.

A abordagem utilizada foi a qualitativa. De acordo com Malhotra (2012), as pesquisas qualitativas não são estruturadas, pois são realizadas com base em pequenas amostras que possibilitam um entendimento contextualizado do problema.

Os meios utilizados para a investigação e alcance dos resultados foram entrevistas semiestruturadas. Entrevistas possuem a capacidade de fornecer os dados necessários mesmo que de forma flexível (GIL, 2008).

A pesquisa foi desenvolvida em três organizações financeiras de diferentes seguimentos: meios de pagamento; instituição financeira; seguradora. A empresa de meios de pagamento é atualmente uma das líderes em sua atuação global, com forte presença no Brasil. A instituição financeira é o maior banco do Brasil quando se trata de rede de atendimento ao cliente. Quanto a seguradora consta em seus resultados como a maior geradora de receita no seu seguimento no Brasil.

Os procedimentos utilizados na busca dos dados foram obtidos por meio de entrevistas realizadas com um representante de cada empresa. As entrevistas foram realizadas pessoalmente e por telefone na segunda quinzena de setembro tendo duração média de trinta minutos. O roteiro da entrevista foi baseado em perguntas pertinentes ao estudo para atender aos objetivos geral e específicos. Foram solicitados também materiais que pudessem confirmar os dados relatados nas entrevistas.

$\mathrm{Na}$ análise dos dados obtidos, a técnica utilizada foi análise de conteúdo, na qual foram levantadas categorias (Tabela 1) que pudessem responder ao problema de pesquisa de acordo com os assuntos abordados em referencial teórico e as perguntas realizadas nas entrevistas. Segundo Bardin (2010), essa técnica visa obter, por procedimentos e descrição de conteúdo adquirido das mensagens, indicadores que outorgam a conclusão de conhecimentos correlacionados as variáveis adquiridas nas mensagens. 


\section{CATEGORIAS}

1 Percepção de Fintech

2 Ações de Parcerias entre Instituições Financeiras e Fintechs

3 Oportunidades

4 Desafios

\section{Tabela 1 - Categorias}

Fonte: Elaborado pelos autores.

A categoria denominada "Percepção de Fintech" aborda o entendimento dos entrevistados no que se refere a visão geral da presença das Fintechs no mercado. A categoria nomeada "Ações de Parcerias entre Instituições Financeiras e Fintechs" abrange as respostas dos entrevistados quanto as ações que as instituições financeiras estão realizando para se aproximarem das Fintechs. A categoria intitulada "Oportunidades" contempla as considerações dos entrevistados sobre as possibilidades que as Fintechs podem gerar. A categoria "Desafios" busca apresentar as considerações referentes às dificuldades identificadas pelas instituições financeiras frente a atuação das Fintechs no mercado.

\section{APRESENTAÇÃO E DISCUSSÃO DOS DADOS}

Os participantes desta pesquisa foram os representantes de três organizações financeiras de diferentes seguimentos: meios de pagamento; instituição financeira; seguradora. Com base nos pontos abordados no referencial teórico, os entrevistados foram questionados sobre startups e Fintechs (Tabela 2). Os dados apresentados foram classificados em categorias como apresentado na figura 3.

\begin{tabular}{|c|c|c|}
\hline CATEGORIAS & & COMENTÁRIOS \\
\hline \multirow{4}{*}{ Percepções de Fintech } & \multirow{2}{*}{$\begin{array}{l}\text { Meios de } \\
\text { Pagamento }\end{array}$} & $\begin{array}{l}\text { "Uma visão que eu tenho, as Fintechs vieram para } \\
\text { brigar com os bancos, os bancos não gostam, acho que } \\
\text { ainda tem um pouco dessa insegurança. Ao mesmo } \\
\text { tempo começamos a ver muitos bancos que olham as } \\
\text { Fintechs como oportunidade." }\end{array}$ \\
\hline & & $\begin{array}{l}\text { "Acredito que já passou essa fase de ver as Fintechs } \\
\text { como vilãs, vejo agora as Fintechs como laboratório, } \\
\text { como experiência, como oportunidade que traz algo } \\
\text { diferenciado." }\end{array}$ \\
\hline & $\begin{array}{l}\text { Instituição } \\
\text { Financeira }\end{array}$ & $\begin{array}{l}\text { "Eu me aproximo dessas startups, ajudo a colocar nos } \\
\text { eixos essas ideias, que são excelentes, mas muitas vezes } \\
\text { elas não possuem um networking, não conhecem } \\
\text { ninguém e não possuem uma visão executiva para o } \\
\text { negócio." }\end{array}$ \\
\hline & Seguradora & $\begin{array}{l}\text { "O mercado de Fintechs no Brasil ainda é incipiente } \\
\text { apesar de já ter empresas mais maduras no estágio de } \\
\text { investimentos e na condição de serem parceiras. Mas } \\
\text { em termos de quantidade são pequenas e poucas." } \\
\text { "As empresas estão sendo afetadas na forma de } \\
\text { trabalhar por causa dessas Fintechs que estão } \\
\text { aparecendo." }\end{array}$ \\
\hline $\begin{array}{lrr}\text { Ações } & \text { de } & \text { Parceria } \\
\text { entre } & \text { Instituições } \\
\text { Financeiras e Fintechs }\end{array}$ & $\begin{array}{l}\text { Meios de } \\
\text { Pagamento }\end{array}$ & $\begin{array}{l}\text { "A instituição apoia e realiza mentorias de programas } \\
\text { de Fintechs como, por exemplo, a Google Camp. Nós } \\
\text { apoiamos e trazemos para dentro da empresa essas }\end{array}$ \\
\hline
\end{tabular}




\begin{tabular}{|c|c|c|}
\hline & & $\begin{array}{l}\text { Fintechs para realizar um programa de mentoria e } \\
\text { cultura." }\end{array}$ \\
\hline & & $\begin{array}{l}\text { "A aproximação já começou e vem crescendo } \\
\text { fortemente, ela traz essa visão de Fintech para a } \\
\text { empresa com visão mais tradicional, de como são feitos } \\
\text { os produtos, para que essas empresas tradicionais } \\
\text { possam se arriscar mais, fazer um negócio pequeno, que } \\
\text { conforme for acontecendo, as coisas serão ajustadas ao } \\
\text { longo do processo." }\end{array}$ \\
\hline & $\begin{array}{l}\text { Instituição } \\
\text { Financeira }\end{array}$ & $\begin{array}{l}\text { "Um exemplo de parceria, eu sei que a instituição na } \\
\text { qual trabalho já andou conversando com diversas } \\
\text { Fintechs na busca de possibilidade de somar esforços e } \\
\text { fazer parcerias." }\end{array}$ \\
\hline & Seguradora & $\begin{array}{l}\text { "O que tenho percebido é que está começando a ter essa } \\
\text { aproximação entre Fintechs e os bancos tradicionais." } \\
\text { "Vejo as Fintechs agora como oportunidades em fazer } \\
\text { eventuais parcerias ou fazer uma aquisição." }\end{array}$ \\
\hline & & $\begin{array}{l}\text { "Maneira prática, a XP Investimentos era uma Fintech } \\
\text { que o Itaú comprou pois estava incomodado, pois assim } \\
\text { não está perdendo clientes e nem deixando de crescer." }\end{array}$ \\
\hline & $\begin{array}{l}\text { Meios de } \\
\text { Pagamento }\end{array}$ & $\begin{array}{l}\text { "Nubank ele saiu com o produto dele de cartão digital } \\
\text { que ninguém acreditou e que começou a fazer barulho, } \\
\text { sem entrar na discussão se é rentável ou não, possuem } \\
\text { uma base de quase um bilhão de clientes, estimulando } \\
\text { assim as empresas a querer fazer alguma coisa." }\end{array}$ \\
\hline Oportunidades & $\begin{array}{l}\text { Instituição } \\
\text { Financeira }\end{array}$ & $\begin{array}{l}\text { "Os bancos têm visto isso como uma espécie de ameaça } \\
\text { pulverizada em alguns negócios que eles atuam, mas eu } \\
\text { tenho visto muitos bancos se aproximando das Fintechs } \\
\text { para aprender e formar parcerias." } \\
\text { "Os bancos podem usar as Fintechs no conceito de open } \\
\text { banking para entregar essa mesma experiência por meio } \\
\text { de parcerias." }\end{array}$ \\
\hline & Seguradora & $\begin{array}{l}\text { "A outra coisa que eu vejo em segmentos grandes, o } \\
\text { que está mais latente é a questão do banco digital, } \\
\text { Banco Original, Nubank que vai entrar na área, nós } \\
\text { temos recebido três solicitações, para o início do ano, } \\
\text { mais bancos digitais entrando no mercado sem agência, } \\
\text { nesse conceito de banco digital que já começa a parecer } \\
\text { não dá para parecer que não existe. É uma realidade. O } \\
\text { que começa a fazer os bancos olharem como a forma } \\
\text { digital deles de se relacionar com clientes, fazer um } \\
\text { chat como canal de atendimento com o cliente. Eu } \\
\text { acredito que tem uma influência de banco digital em } \\
\text { instituições financeiras." }\end{array}$ \\
\hline & & "Eu não vejo o Banco Central regulando" \\
\hline Desafios & Pagamento & $\begin{array}{l}\text { "O mercado não ficará mais aberto e sim mais } \\
\text { regulado." }\end{array}$ \\
\hline
\end{tabular}




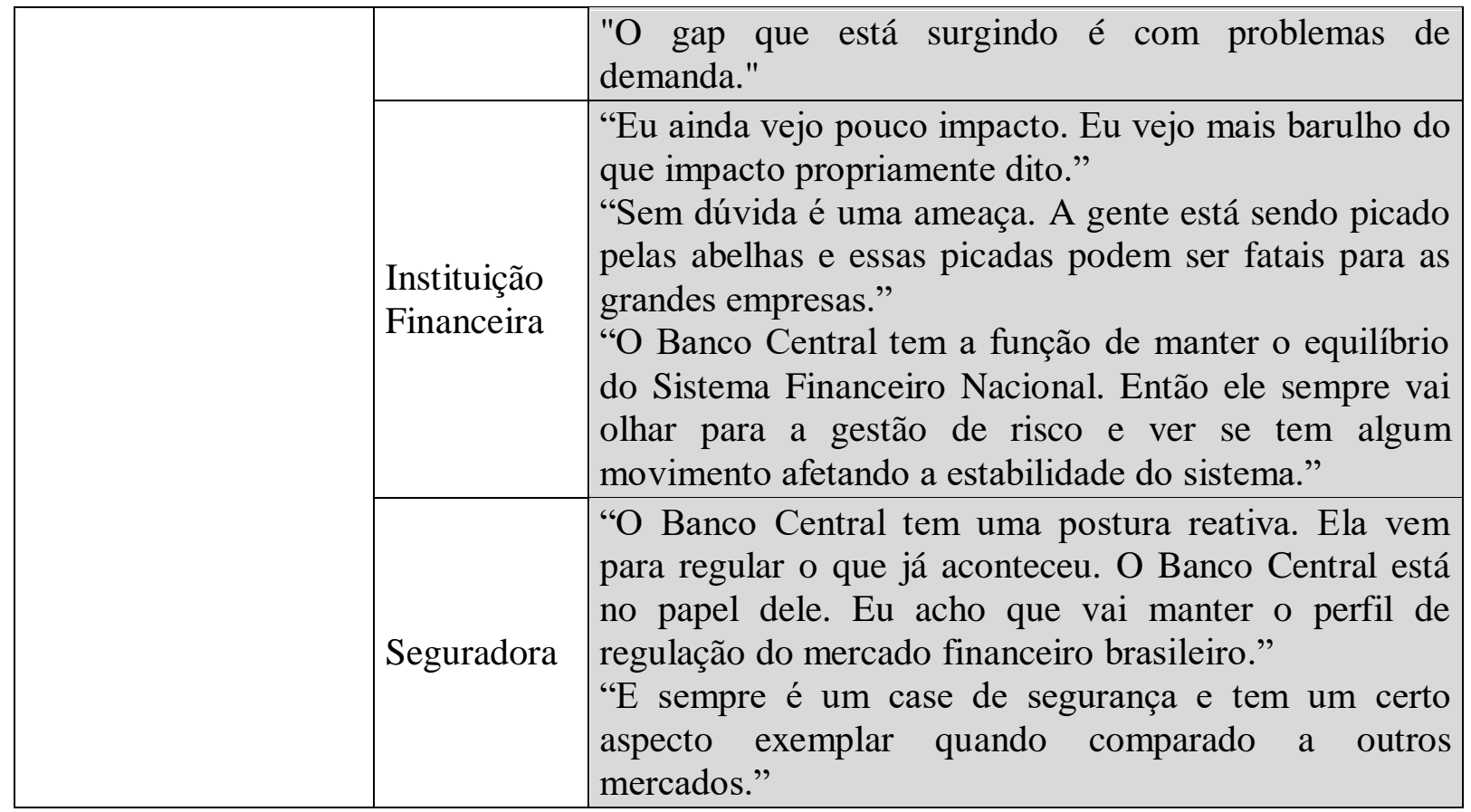

Tabela 2 - Resultados sobre as categorias

Fonte: Elaborado pelos autores.

Durante a pesquisa verificou-se que os entrevistados acreditam que as Fintechs representam um grande crescimento de presença no mercado apesar de ser considerado um mercado pouco desenvolvido em relação aos países desenvolvidos. Contudo, ainda assim, as organizações financeiras estão sendo afetadas na forma de trabalhar devido as Fintechs que estão surgindo.

Quanto às ações de parcerias entre instituições financeiras e Fintechs, os entrevistados percebem que é um campo promissor e que pode ser explorado sendo vantajoso tanto para as organizações financeiras quanto para as Fintechs. No caso das organizações financeiras, principalmente relacionado às especializações trazidas pelas Fintechs e o seu modo de pensar. Já para as Fintechs, a possibilidade de aprendizado com grandes empresas, por meio de mentorias e da geração de escala de negócios.

De acordo com os entrevistados, faz-se necessário buscar as parcerias para que o mercado sempre possa estar atualizado de forma dinâmica e eficaz. Deste modo, as grandes instituições procuram adquirir essas startups que estão trazendo concorrência ou estão apenas ocasionando uma melhor parceria para o seu negócio, diminuindo os processos e gastos com a mão-de-obra com suas inovações e tecnologias empregadas.

Conforme Puschmann (2017), as Fintechs são como inovações incrementais ou disruptivas induzidas por desenvolvimentos de tecnologia da informação, resultando em novos modelos de negócios intra ou inter-organizacionais evidenciando que as parcerias entre as startups e as grandes organizações devem considerar as Fintechs como parceiros e não como concorrentes.

Um ponto de destaque dentre as oportunidades mencionadas pelos entrevistados refere-se a entrada dos bancos totalmente digitais. Neste caso, as grandes instituições se sentem obrigadas a buscarem novas ferramentas digitais que facilitem o relacionamento com clientes que estão cada vez mais exigentes com os produtos e serviços que consomem. Nesta perspectiva, de acordo com Chuen e Teo (2016), são apresentadas as setes principais características dos modelos de negócios trazidos pelas Fintechs. Dentre elas, cabe mencionar a de simplicidade da proposta de valor e os fatores diferenciadores fáceis de compreender pelos clientes com processos de negócios altamente focados e transparentes. 
Quanto aos desafios elencados pelos entrevistados, mesmo com pouco impacto nos resultados das organizações financeiras, as Fintechs já representam uma grande ameaça tornando-as um desafio atual para as instituições financeiras se adaptarem e se readequarem.

Além disso, para ser analisado como as melhores oportunidades e parcerias que podem surgir no futuro entre as empresas tradicionais e Fintechs, os entrevistados colocam em discussão, que é necessária a regulamentação dessas novas empresas. Porém deve-se analisar com cautela esta regulamentação para não haver um excesso de burocracia que impeça o crescimento do setor. De acordo com Hillbrecht (1999), o Sistema Financeiro é um dos setores mais regulados do mundo com o objetivo de garantir todo o seu funcionamento. Diante disto, as Fintechs vão precisar se adaptar às regulações a medida que crescem e formam parcerias.

\section{CONSIDERAÇÕES FINAIS}

O presente estudo teve como objetivo geral identificar como as Fintechs se configuram oportunidades ou ameaças para as grandes instituições financeiras no Brasil. E como objetivos específicos: analisar as percepções sobre as Fintechs; observar as parcerias que podem surgir entre as instituições financeiras e as Fintechs; identificar os desafios das Fintechs com o mercado.

Ao analisar as percepções sobre as Fintechs identificou-se que as mesmas estão presentes no mercado e em constante crescimento. Apesar de em um número pouco expressivo, algumas Fintechs já são desenvolvidas o suficiente para receberem investimentos e serem compradas por grandes instituições financeiras.

Quanto às parcerias que podem surgir entre as instituições financeiras e as Fintechs notou-se a relevância que esses novos modelos de negócios têm ao beneficiar os consumidores por meio da junção do moderno com o tradicional para o desenvolvimento de novos produtos e serviços. Tais parcerias ainda implicam na possibilidade de gerar facilidades para os clientes, menos burocracia, mais oportunidades de crédito rápido para investimentos em curto prazo, entre outros.

Ao identificar os desafios das Fintechs com o mercado a principal indicação consiste na ausência de uma regulação que permeie esses novos modelos de negócios.

Por fim, ao se analisar as oportunidades e desafios apresentados pelos entrevistados conclui-se que as Fintechs podem ser consideradas uma oportunidade as instituições que estiverem atentas ao surgimento de novas possibilidades no mercado financeiro. Diante do exposto, os objetivos desse estudo foram alcançados e o problema de pesquisa respondido.

As limitações encontradas para a realização da pesquisa foi o fato de se tratar de um tema novo e, consequentemente, a escassez de informações e material de pesquisa.

Para agenda futura, sugere-se que o assunto seja pesquisado junto a um maior número de entrevistados e representantes de outras instituições financeiras no Brasil. Sugere-se ainda que um estudo comparativo seja realizado com o intuito de identificar se as percepções apresentadas no mercado brasileiro são similares àquelas apresentadas em outros países.

\section{REFERÊNCIAS}

ALECRIM, E. O que é fintech? Info Wester, 2016. Disponível em: http://www.infowester.com/fintech.php. Acesso em: 23 abr. 2019.

ALVES, J. V. Entrando na onda da Tecnologia disruptiva. Fale Olá, 2016 Disponével em: http://www.faleola.com.br/emailpublic/wordpress/?p=321. Acesso em: 25 abr. 2019.

ARNER, D. W.; BARBERIS, J.; BUCKLEY, R. P. The evolution of Fintech: A new postcrisis paradigm. Geo. J. Int'I L., v. 47, p. 1271, 2015. 
BANCO CENTRAL DO BRASIL. Composição e segmentos do Sistema Financeiro Nacional. Banco Central do Brasil, 2017. Disponível em: https://www.bcb.gov.br/pre/composicao/composicao.asp. Acesso em: 24 abr. 2019.

BARBERIS, J. The rise of finTech: Getting Hong Kong to lead the digital financial transition in APAC. Fintech Report. Fintech HK, v. 13, n. 4, 2014.

BARDIN, L. Análise de conteúdo. Edições 70. Lisboa. Portugal, 2011.

BETTINGER, A. Fintech: A series of 40 time shared models used at Manufacturers Hanover Trust Company. Interfaces, p. 62-63, 1972.

BOWER, J. L.; CHRISTENSEN, C. M. Disruptive technologies: catching the wave. 1995.

CAVALCANTE, F. Mercado de capitais. Elsevier Brasil, 2002.

CHRISTENSEN, C. M.; RAYNOR, M. E.; MCDONALD, R. What is disruptive innovation.

Harvard Business Review, v. 93, n. 12, p. 44-53, 2015.

CHUEN, K.; LEE, D.; TEO, E. G. S. Emergence of fintech and the LASIC principles. Journal of Financial Perspectives, v. 3, n. 3, 2015.

DRUCKER, P. F. The discipline of innovation. Harvard business review, v. 80, p. 95-104, 2002.

FOSTER, R. N. Innovation: The attacker's advantage. Summit books, 1988.

FRAME, W. S. Technological change, financial innovation, and diffusion in banking. Leonard N. Stern School of Business, Department of Economics, 2014.

GIL, A. C. Métodos e técnicas de pesquisa social. 6. ed. Editora Atlas SA, 2008.

GIL, A. Como Elaborar projetos de pesquisa, $5^{\text {a }}$ Edição, editora Atlas. São Paulo, p. 184, 2010 .

GIMPEL, H.; RAU, D.; RÖGLINGER, M. FinTech-Geschäftsmodelle im Visier. Wirtschaftsinformatik \& Management, v. 8, n. 3, p. 38-47, 2016.

HADDAD, C.; HORNUF, L. The Emergence of the Global Fintech Market: Economic and Technological Determinants. Institute of Labour Law and Industrial Relations in the European Union (IAAEU), 2016.

HILLBRECHT, R. Economia monetária. Atlas, 1999.

HOCHSTEIN, M. Did Citi Coin the Term 'Fintech'? American Banker, 2015. Disponível em: $\quad$ http://www.americanbanker.com/bankthink/friday-flashback-did-citi-coin-thetermfintech-1076875-1.html. Acesso em: 24 abr. 2019.

HWANG, S. S. What We Need in the Fintech Craz. LG CNS Blog, 2014. Disponível em: http://www.lgcnsblog.com/technology/what-we-need-in-the-fintech-craze. Acesso em: 25 abr. 2019.

JUGEND, D.; MARTINS, T.; OPRIME, P. C.; DA SILVA, S. L. Innovation in industrial clusters: a survey of footwear companies in Brazil. Journal of technology management \& innovation, v. 8, n. 3, p. 45-56, 2013.

MALHOTRA, N. K. Pesquisa de Marketing-: Uma Orientação Aplicada. Bookman Editora, 2012.

MANUAL, O. Guidelines for collecting and interpreting innovation data (2005). A joint publication of OECD and Eurostat, Organization for Economic Co-Operation and Development. Statistical Office of the European Communities, 2005.

MORI, T. Financial technology: blockchain and securities settlement. Journal of Securities Operations \& Custody, v. 8, n. 3, p. 208-227, 2016.

PORTER, M. E. How competitive forces shape strategy. Harvard Business School Press, 1991.

PUSCHMANN, T. Fintech. Business \& Information Systems Engineering, v. 59, n. 1, p. 69-76, 2017.

RIEG, Christian. Les défaillances d'entreprises. Insee Première, n. 866, 2002. 
ALT, R.; SACHSE, S. Banking innovation. Gabler Bank-Lexikon, 14th edn. Springer Gabler, Wiesbaden, p. 161-162, 2012.

SCHUMPETER, J. A. Teoria do desenvolvimento econômico: uma investigação sobre capital, crédito, juro e o ciclo econômico. Traducao Maria Silva Possas. São Paulo: Abril Cultural, 1982.

SCHUMPETER, J. A. Theorie der wirtschaftlichen entwicklung.[Português] Teoria do desenvolvimento econômico: uma investigação sobre lucros, capital, credito, juro e o ciclo econômico. São Paulo: Abril Cultural, 1997.

TUFANO, P. Financial innovation. In: Handbook of the Economics of Finance. Elsevier, 2003. p. 307-335.

WALKER, A. Banking without banks: Exploring the disruptive effects of converging technologies that will shape the future of banking. Journal of Securities Operations \& Custody, v. 7, n. 1, p. 69-80, 2014.

WARSCHAUER, C. L. A programação financeira das sociedades de financiamento, crédito e investimento. Revista de Administração de Empresas, v. 14, n. 1, p. 33-57, 1974. 